\title{
The Relationship Between the Free Pool of Proline and Collagen Content in Human Liver Cirrhosis
}

\author{
David Kershenobich, Francisco J. Fierro, and Marcos Rojkind \\ From the Departamento de Gastroenterología, Patología y Bioquímica, \\ Instituto Nacional de la Nutrición, México 7, D. F.
}

\begin{abstract}
A в S T R A C T The free proline, free glutamic acid, and total collagen contents of the livers of cirrhotic and noncirrhotic patients were determined. The amounts of free proline in the sera of the patients were also determined. The results indicated that certain metabolic changes occurred in cirrhotic livers of humans that were similar to the metabolic changes observed previously in $\mathrm{CCl}_{4}$-induced cirrhosis in the rat. The amount of free proline was coordinate with the increase in total collagen, and both were inversely related to the amount of free glutamic acid. The average proline concentration in sera of cirrhotic patients was not higher than that of non cirrhotic patients, suggesting that the metabolic alteration noted above is a local event in the liver related to fibrogenesis. These and other results suggest that the pool size of free proline may play a prime role in regulation of collagen biosynthesis in liver cirrhosis.
\end{abstract}

\section{INTRODUCTION}

Work from different laboratories suggests that increased deposition of collagen (1-6) and not collapse of the preexisting reticulum framework $(7,8)$ is a main factor in human and experimental hepatic fibrosis. Also, liver slices from rats made cirrhotic by chronic administration of $\mathrm{CCl}_{t}$ have been shown to incorporate proline $-{ }^{14} \mathrm{C}$ into protein-bound hydroxyproline, while normal rat liver slices under similar conditions do not produce detectable amounts of radioactive collagen (9).

Recent work from our laboratory (10) has shown important changes in the free pools of proline and glu-

Dr. Kershenobich's present address is the Medical Unit, The Royal Free Hospital, North Western Branch, Lawn Road, N.W.3, London, Great Britain.

Dr. Roikind's present address is Departamento de Genétira y Biología Celular, Centro de Investigación y de Estudios Avanzados, Instituto Politécnico Nacional, Apto. Postal 14 740, Méxi-o 14, D. F.

Received for publication 20 May 1970 and in rerised form 6 July 1970. tamic acid in rats made cirrhotic by administration of $\mathrm{CCl}_{4}$. These changes precede biosynthesis of collagen, measured as protein-bound hydroxyproline, and increase in protocollagen-proline hydroxylase already demonstrated in experimental hepatic fibrosis $(9,10)$. Furthermore, in such animals there was generally good correlation with respect to increase in the hepatic free pool of proline, total hepatic collagen, and capacity of the livers to synthesize collagen in vitro.

The experiments described in this communication were performed with tissues from patients to determine what early metabolic changes correlate directly with the extent of hepatic fibrosis.

\section{METHODS}

Source of materials. All the liver and blood samples used in this study were obtained from hospitalized patients. Control subjects were patients with diseases other than cirrhosis who showed normal liver function tests. Liver specimens were taken during exploratory laparotomy or from autopsy specimens. The latter were used only when less than $2 \mathrm{hr}$ elapsed between time of death and autopsy. All samples were kept on ice and used immediately after they were obtained.

Isolation of free glutamic acid and proline. Samples corresponding to about $1 \mathrm{~g}$ of liver were accurately weighed and homogenized with $3.5 \mathrm{ml}$ of cold Ringer's bicarbonate buffer (10). Immediately thereafter the protein was precipitated by addition of 3 volumes of absolute ethanol; and after $1 \mathrm{hr}$ at $4^{\circ} \mathrm{C}$, the samples were centrifuged at $700 \mathrm{~g}$ for $15 \mathrm{~min}$. The supernatant fluid containing the free amino acids was decanted and the precipitate washed three times with ethanol: water $(3: 1)$. The precipitate was used subsequently for the determination of total collagen. The combined supernatant fractions were pooled and evaporated to dryness in a rotary evaporator at $40^{\circ} \mathrm{C}$. The residue was

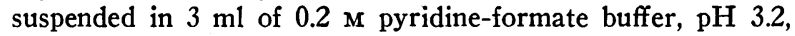
and centrifuged at $700 \mathrm{~g}$ for $15 \mathrm{~min}$ to remove undissolved particles. The clear supernatant fluid was placed on a 1.2 $\times 40 \mathrm{~cm}$ column of AG 50W-X8 (200400 mesh), ${ }^{1}$ equilibrated previously with $0.2 \mathrm{M}$ pyridine-formate buffer at 30 $\mathrm{ml} / \mathrm{hr}$. Fractions containing $2.4 \mathrm{ml}$ each were collected, and appropriate aliquots were used for determination of proline by the method of Troll and Lindsley (11). 
A second sample corresponding to about $1 \mathrm{~g}$ of liver was accurately weighed and treated as previously described except that the fraction containing the free amino acids was dissolved in $3 \mathrm{ml}$ of water instead of pyridine-formate buffer. The sample then was centrifuged at $700 \mathrm{~g}$ for $15 \mathrm{~min}$ and the clear supernatant fluid placed on a $1.2 \times 10 \mathrm{~cm}$ column of AG 1-X8 (200-400 mesh $)^{1}$ in acetate form. The column was washed with $30 \mathrm{ml}$ of distilled water. Glutamic acid was eluted from the column with $0.5 \mathrm{~m}$ acetic acid and collected in fractions of $2.4 \mathrm{ml}$ each. The amino acid was then determined by the ninhydrin method (12).

A third sample containing $200-300 \mathrm{mg}$ of liver was accurately weighed and dried to constant weight at $104^{\circ} \mathrm{C}$. The wet weights were related to the dry weights and the results expressed as micromoles of amino acids per gram of dry tissue.

Determination of total liver collagen. The precipitate obtained after removing the free amino acids was suspended in $2 \mathrm{ml}$ of water and transferred to an ampule for hydrolysis. An equal volume of $12 \mathrm{~N} \mathrm{HCl}$ was added and the ampule sealed under vacuum. The sample was hydrolyzed for $24 \mathrm{hr}$ at $104^{\circ} \mathrm{C}$ and the excess $\mathrm{HCl}$ was removed in a rotary evaporator. The residue was suspended in $3 \mathrm{ml}$ of $0.2 \mathrm{M}$ pyridine-formate buffer, $\mathrm{pH} 3.2$, and in this form was placed on a $1.2 \times 40 \mathrm{~cm}$ column of AG $50 \mathrm{~W}-\mathrm{X} 8 \quad(200-400$ mesh $)^{1}$ previously equilibrated with the same pyridineformate buffer. Hydroxyproline was eluted with the same buffer flowing through at a rate of $30 \mathrm{ml} / \mathrm{hr}$. Fractions containing $2.4 \mathrm{ml}$ each were collected and appropriate aliquots were used for hydroxyproline determination by the method of Woessner (13). The amounts of collagen was calculated from hydroxyproline content assuming that 96 $\mathrm{mg}$ of collagen contain $100 \mu$ moles of hydroxyproline.

Determination of free proline in serum. $3 \mathrm{ml}$ of serum were mixed with 3 volumes of absolute ethanol and the mixture was allowed to stand for $1 \mathrm{hr}$ at $4^{\circ} \mathrm{C}$. The proteins were then removed by centrifugation at $700 \mathrm{~g}$ for $15 \mathrm{~min}$ The supernatant fluid was evaporated to dryness in a rotary evaporator and the residue was dissolved in $3 \mathrm{ml}$ of $0.2 \mathrm{M}$ pyridine-formate buffer, $\mathrm{pH}$ 3.2. Free proline was separated by column chromatography as described. Results were expressed as micromoles of proline per milliliter of serum.

Histological studies. Samples of the livers used in these experiments were fixed in $10 \%$ formalin and embedded in paraffin. Thin sections were prepared and stained respectively with hematoxylin eosin, silver, and trichromic stains. The degree of fibrosis was classified in an arbitrary manner in the following four grades: grade 1, discrete portal fibrosis without formation of nodules; grade 2, portal fibrosis with subcapsular nodules; grade 3, irregular portal fibrosis; and grade 4, irregular portal fibrosis with signs of collapse of reticulum. Histological analysis of the slides was performed independent of knowledge obtained by chemical studies.

\section{RESULTS}

In agreement with published normal values, the two normal livers analyzed in the present studies contained respectively $2.2 \mathrm{mg}$ and $3.0 \mathrm{mg}$ of collagen per $\mathrm{g}$ on a dry weight basis (see Table I). The cirrhotic livers that were analyzed showed, as expected, an increase in total

\footnotetext{
${ }^{1}$ Obtained from Bio-Rad Laboratories, Richmond, Calif.
}

TABLE I

Pool Sizes of Proline and Glutamic Acid and Total Collagen Contents of Cirrhotic and Noncirrhotic Patients

\begin{tabular}{lcccc}
\hline $\begin{array}{c}\text { Histological } \\
\text { diagnosis }\end{array}$ & $\begin{array}{c}\text { Degree of } \\
\text { fibrosis }\end{array}$ & $\begin{array}{c}\text { Total } \\
\text { collagen* }\end{array}$ & $\begin{array}{c}\text { Free } \\
\text { prolineł }\end{array}$ & $\begin{array}{c}\text { Free } \\
\text { glutamic } \\
\text { acid } \ddagger\end{array}$ \\
\hline Normal & 0 & 2.2 & 1.3 & 8.7 \\
Normal & 0 & 3.0 & 1.1 & 9.5 \\
Portal cirrhosis & ++ & 7.1 & 2.8 & - \\
Portal cirrhosis & ++ & 7.1 & 2.9 & 3.1 \\
Portal cirrhosis & ++ & 7.2 & 2.8 & 2.9 \\
Portal cirrhosis & +++ & 8.3 & 2.6 & 2.9 \\
Portal cirrhosis & ++++ & 9.4 & 3.5 & 1.6 \\
Portal cirrhosis & ++++ & 10.5 & 4.6 & 1.8 \\
Portal cirrhosis & ++++ & 11.4 & 5.0 & 1.4 \\
\hline
\end{tabular}

* $\mathrm{mg} / \mathrm{g}$ of dry weight of liver.

$\ddagger \mu$ moles/g of dry weight of liver.

collagen content. As shown in Table $I$, there was a 2.5- to 3.7-fold increase above the normal values.

Histological examination of the liver specimens revealed a portal type of cirrhosis. The degree of fibrosis determined by histological means correlated well with the amount of collagen determined by hydroxyproline analysis (Table I).

Previous work from our laboratory has shown that in hepatic cirrhosis induced in rats with $\mathrm{CCl}_{4}$, the amounts of collagen in the liver is coordinate with the concentration of free proline and inversely related to the concentration of free glutamic acid (10). As shown in Table I, the amounts of free proline and free glutamic acid in livers of cirrhotic patients follow the same pattern obtained in experimental cirrhosis. There is also a linear relationship between the free pool of proline and total collagen content (Fig. 1).

In order to determine if the increase in free proline in the liver was reflected in the free proline content of the blood, serum samples from normal and cirrhotic patients were analyzed. As shown in Table II, the average proline concentration in the sera of cirrhotics was not higher than that of normals.

\section{DISCUSSION}

Very little is known about the mechanisms regulating collagen biosynthesis. Much of the work that has been done is in relation to the final steps of the process, that is, the chemical modifications that take place after the protein has been synthesized (14-18).

Prockop and Juva (14) have suggested that protocollagen, a large molecular weight precursor of collagen in which there is no hydroxyproline and hydroxylysine, is an obligatory biosynthetic intermediate. In this regard, Takeuchi and Prockop (15) have presented data to suggest that, in human liver cirrhosis, protocollagen- 


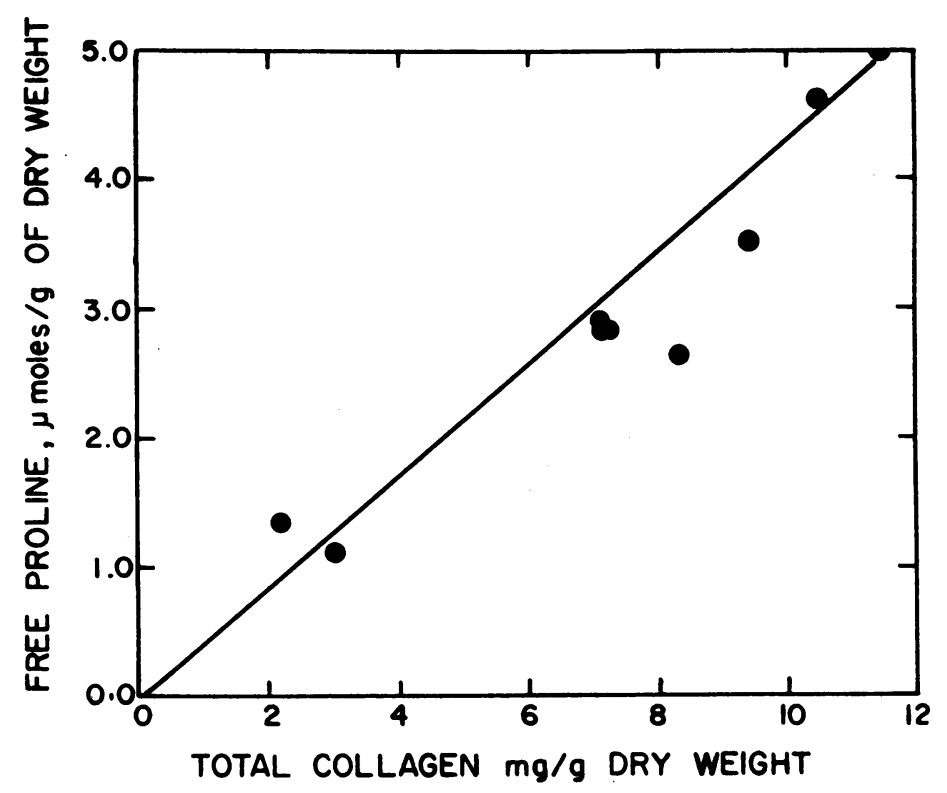

FIgURE 1 A plot of the concentration of free proline versus collagen content in a group of cirrhotic and noncirrhotic patients. The line was drawn by the least square method. The $Y$ intercept was -0.0289 at $X=0$, and the slope of the line was 0.4331 .

proline hydroxylase, the enzyme responsible for the hydroxylation of protein-bound proline residues, increases in amount or activity before the formation of extracellular collagen. Goldberg and Green (16, 17) suggested that in several fibroblastic and nonfibroblastic cell lines protocollagen may act as an inducer for hydroxylase synthesis or that the synthesis of both proteins might be controlled by a single genetic unit analogous to the operon in bacteria.

Gribble, Comstock, and Udenfriend (18) demonstrated that fibroblasts in culture are able to accumulate and secrete a nonhydroxylated "collagen;" however, their results suggest that the increase in hydroxylation is a

TABLE II

Concentrations of Free Proline in Sera of Cirrhotic and Noncirrhotic Patients

\begin{tabular}{|c|c|}
\hline Cirrhotic patients & Noncirrhotic patients \\
\hline \multicolumn{2}{|c|}{ 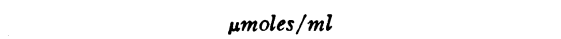 } \\
\hline 0.136 & 0.121 \\
\hline 0.142 & 0.121 \\
\hline 0.100 & 0.094 \\
\hline 0.182 & 0.218 \\
\hline 0.075 & 0.137 \\
\hline- & 0.170 \\
\hline- & 0.093 \\
\hline $\begin{array}{r}\text { Mean value } \pm S D \\
(0.127 \pm 0.036)\end{array}$ & $\begin{array}{r}\text { Mean value } \pm \mathrm{SD} \\
(0.136 \pm 0.041)\end{array}$ \\
\hline
\end{tabular}

result of activation of an inactive precursor of the hydroxylase.

Liver cirrhosis induced in rats by chronic administration of $\mathrm{CCl}_{4}$ is an experimental model for study of the biosynthesis of collagen and its regulation $(9,10)$. With this system one can study the late steps of collagen synthesis but one can also study the modifications that take place at earlier stages of collagen biosynthesis. Accordingly, Rojkind and Diaz de León (10) were able to show that the concentration of free proline in the liver rose proportionately to the concentration of collagen and was inversely proportional to the concentration of free glutamic acid. Since the collagen molecule contains $20 \%$ of proline plus hydroxyproline and the content of free proline of the liver was directly related to the capacity to synthesize collagen, it was suggested that indeed a limiting condition in the synthesis is the size of the free proline pool.

The results obtained in the present communication indicate that human portal cirrhosis of the liver is accompanied by hepatic metabolic changes similar to those observed in experimental cirrhosis in the rat. Thus, the free proline concentration rose proportionately to the concentration of collagen and was inversely proportional to the concentration of free glutamic acid.

It has been shown that liver slices from cirrhotic rats accumulate approximately 100 times more proline from precursor glutamic acid- ${ }^{14} \mathrm{C}$ than did liver slices from normal animals (10). Although the decrease in glutamic 
acid observed in human portal cirrhosis could also be related to a more active proline biosynthesis from its precursor glutamic acid, the results cannot be fully explained by this mechanism. Rojkind and Diaz de León (10) showed in experimental cirrhosis in the rat that only $5 \%$ of the added glutamic acid was converted to proline. Accordingly, the increase in free proline observed in human portal cirrhosis could be due to active conversion of glutamic acid to proline, and the decrease in glutamic acid could be due to the broader effects of cirrhosis on liver metabolism.

The increase in free proline in the liver was not accompanied by an increase in free proline concentration of the sera of patients, suggesting that this metabolic alteration was a local event of the liver and was related to the increase collagen biosynthesis in hepatic fibrosis.

More work has to be done to establish if the amount of free proline in the liver directly regulates the biosynthesis of collagen. At this point one cannot rule out that the increase in free proline occurs parallel with the activation of collagen synthesis as a result of a primary event governing both.

\section{ACKNOWLEDGMENT}

We wish to express our appreciation to Professor Sam Seifter for his interest, criticism, and help in preparing the manuscript.

\section{REFERENCES}

1. Morrione, T. G. 1947. Quantitative study of collagen content in experimental cirrhosis. J. Exp. Med 85: 217.

2. Kent, G., G. Fels, A. Dubin, and H. Popper. 1959. Collagen content based on hydroxyproline determinations in human and rat livers. Lab. Invest. 8: 507.

3. Popper, H., F. Schaffner, and F. Paronetto. 1960. Mechanism of hepatic fibrosis. Fed. Proc. 19: 185.

4. Popper, H., F. Paronetto, F. Schaffner, and V. Perez. 1961. Studies on hepatic fibrosis. Lab. Invest. 10: 265.
5. Meader, R. D. 1963. Treatment of nutritional cirrhosis in rats with choline and methionine; with special reference to fibrogenesis and fibroclasia. Anat. Rec. 145: 123.

6. Stenger, R. J. 1965. Fibrogenesis along the hepatic sinusoids in carbon tetrachloride-induced cirrhosis. An electron microscopic study. Exp. Mol. Pathol. 4: 357.

7. Hartroft, W. S. 1950. Accumulation of fat in liver cells and in a lipodiastemata preceding experimental dietary cirrhosis. Anat. Rec. 106: 61.

8. Hartroft, W. S., and J. H. Ridout. 1951. Pathogenesis of the cirrhosis produced by choline deficiency. Escape of lipid from fatty hepatic cysts into the biliary and vascular systems. Amer. J. Pathol. 27: 951.

9. Huberman, A., A. Recio, and M. Rojkind. 1969. Collagen biosynthesis in normal and cirrhotic rat liver slices. Proc. Soc. Exp. Biol. Med. 131: 200.

10. Rojkind, M., and L. Diaz de León. 1970. Collagen biosynthesis in cirrotic rat liver slices. A regulatory mechanism. Biochim. Biophys. Acta. In press.

11. Troll, W., and J. Lindsley. 1955. A photometric method for the determination of proline. J. Biol. Chem. 215: 655.

12. Rosen, H. 1957. A modified ninhydrin colorimetric analysis for amino acids. Arch. Biochem. Biophys. 67: 10.

13. Woessner, J. F. 1961. The determination of hydroxyproline in tissue and protein samples containing small proportions of this imino acid. Arch. Biochem. Biophys. 93: 440.

14. Prockop, D. J., and K. Juva. 1965. Synthesis of hydroxyproline in vitro by hydroxylation of proline in a precursor of collagen. Proc. Nat. Acad. Sci. U. S. A. 53: 661 .

15 Takeuchi, T., and D. J. Prockop. 1969. Protocollagen proline hydroxylase in normal liver and in hepatic fibrosis. Gastroenterology. 56: 744.

16. Goldberg, B., and H. Green. 1968. The synthesis of collagen and protocollagen hydroxylase by fibroblastic and nonfibroblastic cell lines. Proc. Nat. Acad. Sci. U. S. A. 59: 1110.

17. Goldberg, B., and H. Green. 1969. Relation between collagen synthesis and collagen proline hydroxylase activity in mammalian cells. Nature (London). 221: 267.

18. Gribble, J. T., J. P. Comstock, and S. Udenfriend. 1969. Collagen chain formation and peptidyl proline hydroxylation in monolayer tissue cultures of L-929 fibroblasts. Arch. Biochem. Biophys. 129: 308. 